\title{
Amour (protection)
}

(Extrait de Le prix du sang chez les Berbères de l'Atlas, Mémoire présenté par divers savants à l'Académie des Inscriptions et Belleslettres, t. XV, 1964, p. 34-36.)

\section{Jacques-Meunié}

\section{OpenEdition}

\section{Journals}

Édition électronique

URL : http://journals.openedition.org/encyclopedieberbere/2480

DOI : 10.4000/encyclopedieberbere. 2480

ISSN : 2262-7197

\section{Éditeur}

Peeters Publishers

\section{Édition imprimée}

Date de publication : 1 septembre 1986

Pagination : 604-605

ISBN : 2-85744-282-3

ISSN : 1015-7344

\section{Référence électronique}

D. Jacques-Meunié, « Amour (protection) », Encyclopédie berbère [En ligne], 4 | 1986, document A199, mis en ligne le 01 décembre 2012, consulté le 12 octobre 2020. URL : http://journals.openedition.org/ encyclopedieberbere/2480; DOI : https://doi.org/10.4000/encyclopedieberbere.2480

Ce document a été généré automatiquement le 12 octobre 2020

(ㄷ) Tous droits réservés 


\section{Amour (protection)}

(Extrait de Le prix du sang chez les Berbères de l'Atlas, Mémoire présenté par divers savants à l'Académie des Inscriptions et Belleslettres, t. XV, 1964, p. 34-36.)

\section{Jacques-Meunié}

1 Les Imazirhene désignent sous le nom d'amour la protection accordée à l'hôte ou au réfugié, à celui qui s'est placé sous l'égide d'une personne, ou qui se trouve dans un lieu inviolable, c'est ce que les Kabyles appellent l'anaïa. Cet amour, cette protection, peut être accordée volontairement, ou bien elle peut être possédée de plein droit: cette dernière forme de protection est celle que les coutumes attachent à certains lieux et à certaines personnes.

2 Ce principe de l'inviolabilité est très respecté, c'est en son nom qu'aucun acte violent ou mauvais ne doit être commis dans les lieux protégés, aussi la vengeance ou le talion ne peuvent-ils s'y exercer.

3 Parmi les lieux inviolables : celui d'un moussem, grande foire annuelle ou saisonnière ; ceux des souqs, des marchés, et des chemins ou des voies de communication aboutissant à ces lieux de réunion. Là, les vengeurs n'ont pas le droit de tuer le meurtrier car il se trouve sous la protection de la tribu ou de la fraction sur le territoire de laquelle se tient le marché. Les tombeaux des saints, les zaouïas et les agadirs, magasins fortifiés des tribus, sont eux aussi des lieux inviolables, et leur violation serait une offense au saint qui ne manquerait pas de châtier sévèrement le coupable.

4 Les cérémonies de mariages et les fêtes publiques bénéficient également de l'inviolabilité et protègent un criminel. Celui-ci ne peut non plus être tué dans la tente ou dans la maison d'un tiers car le propriétaire chez lequel s'est réfugié le meurtrier est devenu son protecteur, même si c'est son ennemi, et il tirerait vengeance à son tour de ce meurtre commis sous son toit (Imazirhene, Zemmour, Branès).

5 Toutefois, si le meurtrier appartient à la même tribu que la victime, la vengeance peut s'accomplir en tout temps et en tout lieu, au cours des réunions publiques ou privées, des fêtes, des marchés locaux et sur leurs chemins d'accès... Celui qui viole l'amour, la protection d'un lieu préservé par ses interdits encourt les plus graves des sanctions 
prévues par les coutumes: bannissement à vie, saisie des biens, destruction de la maison, doublement de l'amende fixée pour un crime analogue s'il n'est pas commis dans un lieu protégé.

6 Il existe un autre amour, une autre sauvegarde, celle de la femme, dont la présence éloigne la mort et donne la protection. Un meurtrier poursuivi ou en danger de mort échappe à son ennemi s'il se réfugie au milieu des femmes, ou se met sous la protection d'une femme (Imazirhene, Zemmour, Branès). La femme peut accorder sa protection à tout individu qui la lui demande, sauf à son amant pris avec elle en flagrant délit d'adultère. La protection de la femme s'obtient en faisant le simulacre d'être allaité par elle en lui entourant la taille des deux bras. Toute puissante, elle cesse dès que le protégé a quitté sa protectrice.

7 Il est probable que cet amour, cette sauvegarde, s'explique par l'idée très répandue chez les peuples primitifs, et qui a longtemps subsisté, que la magie est surtout exercée par les femmes. En particulier chez les Berbères, comme chez les anciens Arabes, la femme est un être magique, redoutable et sacré. Les témoignages relatifs au pouvoir de protection de la femme proviennent tous des Imazirhene. Peut-être les Chleuhs, ont-ils eu anciennement des croyances similaires et celles-ci se sont-elles atténuées ou ontelles disparu sous l'influence de l'Islam. Par contre, l'inviolabilité des lieux a conservé tout son prix chez les Chleuhs, notamment celle des marchés, ainsi que l'attestent des règlements coutumiers particuliers à certains souqs.

\section{BIBLIOGRAPHIE}

ARIN F. « Le talion et le prix du sang chez les Berbères marocains », Archives berbères, I, fascicule 2, 1915, p. 62-87.

ASPINION R. Contribution à l'étude du droit coutumier berbère marocain (études sur les coutumes des tribus Zayanes), $2^{\mathrm{e}}$ édition, Moynier, Casablanca-Fès, 1946.

BIARNAY S. « Un cas de régression vers la coutume berbère dans une tribu arabisée », Archives berbères, I, fascicule 4, 1915, p. 219-229.

BRUNO H. « Note sur le statut coutumier des Berbères marocains (Iguerouan du sud, Aït Ndhir, Aït

Mguild), Archives berbères, I, fasc. 3, 1915, p. 135-151.

BRUNO H., BOUSQUET G.H. « Les pactes d'alliance chez les Berbères du Maroc central », Hespéris, 1946. p. 353-371.

QUERLEUX « Les Zemmour », Archives berbères, I, fasc. 2, 1915, p. 12-61.

INDEX

Mots-clés : Droit, Sociologie 